\title{
The Relationship between the NHS (UK) and the Voluntary Sector Organisations in Mental Healthcare Services Delivery: Performance Improvement through Dialogical Collaboration
}

\author{
Kwesi Korsa Aggrey \\ School of Business, University of Lincoln, UK
}

Copyright $(2016$ by authors, all rights reserved. Authors agree that this article remains permanently open access under the terms of the Creative Commons Attribution License 4.0 International License

\begin{abstract}
The study was initiated to explore the difficulties that frequently appear to plague the relationship between the NHS and the Voluntary Sector as regards mental health service delivery. It was found that the performance of the mental healthcare delivery system is subject to a number of criticisms. The latter could be attributed to low levels of collaboration and communication between social actors involved. Based on interviews, focus group discussions and results from the literature a number of possible ways to improve the system were identified. The results of the study are expected to contribute to the improved designed of health care systems and of performance management concerning the mental health services. Various attempts to improve performance in the past were explored and criticised. One important obstacle to success was identified as a lack of understanding in the NHS and in the Voluntary Sector - of the implications of the use of externally generated performance criteria versus the use of internally generated self-organised criteria. A conceptual model was developed to help clarify these notions as management tool. It includes the idea of a spiral development and of 'complete collective satisfaction'.
\end{abstract}

Keywords Performance Improvement Service Delivery, Mental Health Care System, NHS, Third Cybernetics Evolution, Collaboration, Dialogism

\section{Introduction}

With the embedded class system and the formation of the modern state, it became inevitable that some form of state (Government) authority and legitimacy as well as state responsibility to the citizens was necessary. People forming the government, some influential individuals in society became owners of the factors of production, and the rest of the society had to work for them, the working class [52]. As time went by, the working class and their families, and the social democratic parties like the British Labour Party led by Clement Attlee attempted to implement the socialist idea of redistribution of wealth to bring an end to the class division of the society. This was in line with Karl Marx's idea of socialism, where redistribution of wealth and power is achieved through class struggle and a proletarian revolution (ibid). Socialism aimed at an egalitarian society, where social organisation of society advocates state or collective ownership and the administration of the means of production and the distribution of goods and services. However, there were many degrees of social intervention. Some socialists advocated complete nationalisation of the means of production and distribution; others advocated total state control of capital within the market economies [8; 54].

The social democratic party in the UK, the Labour Party, in 1945 was in favour of nationalisation of industries in mixed economies with tax-funded welfare programs. Therefore, when the British Labour Party was voted to power in 1945, it decided to implement this idea of social collective ownership and therefore Nye (Aneurin) Bevan, the then Minister for Health and Housing of the Labour party, introduced a free health service for all (NHS) in 1948. He even went on to attack his own party for not implementing in full the ideas of socialism by taking the main streams of economic activities under the direction and control of the public, the workers. He believed that the individual workers were the power base of the British economy, particularly the working class from the mining communities, where he had had experience of how the miners sacrifice their 'lives for the country' [53].

The appointment of Nye Bevan marked the birth of a new health service. From his knowledge and experience of the Tredegar Cottage Hospital, which was established in 1902 
by the Community Medical Aid Society with the support of other bodies, Bevan had an insight into how hospitals should or could be managed. He thought that the Tredegar Cottage Hospital was an example of what NHS should be. Before the establishment of the Tredegar Cottage Hospital, patients had to pay for the services they received and even patients' surgeries were taking place on their kitchen tables. With the establishment of the Tredegar Cottage Hospital, health care services were made free at the point of delivery. This was made possible by the contributions from the miners and other bodies. It was a remarkable achievement of the Tredegar Cottage Hospital which motivated Bevan into thinking that a free service of the NHS was possible [52; 31]. In 1951, he resigned from his position when the government decided to charge the people for spectacles, dentistry services and prescriptions as a result of growth in the needs of the society, and the fact that the state had to provide more services to its citizens. He felt everything about the NHS should be free at the point of delivery. He felt that the state, by that action, had betrayed the government's responsibility to its citizens.

In February, 1948 the then government published a White Paper in which it was asserted that all "... irrespective of means, age, sex or occupation shall have equal opportunity to benefit from the best and most up-to-date medical and allied services available'; that the service should be 'comprehensive' for all who wanted; that it should be free of charge', and that it should promote good health', 'rather than only the treatment of bad" [30]. It was declared that the service was going to be largely funded by taxation and therefore would be free for the working class, their families and in fact all at the point of delivery. This was clearly declared on July, 1948 in the Daily Mail which stated: "On Monday morning you will wake up in a new Britain, in a state which 'takes over' its citizens six months before they are born, providing care and free services for their birth, for their early years, their schooling, sickness, workless days, widowhood and retirement". [16].

However, it was being argued that, the NHS had not delivered the high-quality treatment and care promised to the citizens. The NHS services which were supposed to be free for the citizens were charged within five years from its inception. A levy of one-shilling for prescription was introduced and this amount was increased in the subsequent years because it was claimed the tax contributions could not meet the cost of the services delivered. Not only did the levies increase, but also doctors' focus changed. Doctors who were encouraged at the beginning of the NHS to treat patients according to their needs had to change their focus because of the imposition of financial constraints on the state departments' budgets; this included the health sector and, for that matter, the mental health units [30].

In the UK, NHS Trusts have traditionally played an important part in the relationships between patients, clinicians and the government. The state and patients tend to trust the norms of the professionals' self-regulation and state licensed procedures, which ensure that health professionals and health care institutions operated in the best interests of patients and the citizens. However, the responsibility to these authorities changed, the Government's policies [Community Care (Residential Accommodation)] [12;35; 40] were all aimed at making the NHS more responsible to patients' needs and more accountable for the quality of care services provided. These Community Care Acts were all as a result of negative media coverage of scandals over medical incompetence in the 1990s. The enquiry into paediatric cardiac surgery in Bristol [55], the conviction of the GP Harold Shipman [15], and the removal of organs from children at Alder Hey Hospital [18] were examples. The change was also necessitated by a group of more informed and potentially demanding patients who, due to political, socio- economic and cultural changes like the introduction of clinical governance, performance scrutinise, and accountability of clinical activities had the power and choice to be part of the decision making process regarding their care [55]. Let now narrow the scope of the NHS (UK) as per this paper to specifics, Lincolnshire Foundation Trust (NHS) in Lincoln and its relationship with the Voluntary Sector organisations in the delivery of mental health care services.

\section{NHS (Lincolnshire Partnership Foundation Trust) and the Voluntary Sector}

Lincolnshire Partnership NHS Trust (now the Lincolnshire Partnership Foundation Trust - LPFT) was formed in June 2002 to provide specialist health services for people in Lincolnshire with a learning disability, mental health or a substance misuse problem. The category includes adults of working age with a mental health, substance misuse health and social care services, child and adolescent mental health services, occupational therapy, primary care mental services, psychological issues, etc. The Trust is intended to function as a service user centred organisation (Lincolnshire Partnership NHS Trust). The vision of the LPFT is "to be the specialist provider of choice for high quality health and social care services for people within the communities we serve" [42]. Its values are derived from the National Service Frameworks and Strategies, and the NHS Plan, which are as follows:

- To put the needs and wishes of service users at the heart of everything;

- To value the contribution of staff and provide a supportive and flexible working environment;

- To work in partnership with other organisations to deliver integrated health and social care services;

- To manage the business of the Trust with integrity by upholding the highest professional ethical and governance standards;

- To strive to achieve excellence through performance and innovation. [42] 
The Trust brings together mental health and learning disability services provided by former NHS Trust and the Lincolnshire County Council Social Services Department. This means that a variety of customs, practices, policies and procedures regarding the relationship with the voluntary sector and approach to organising volunteers were inherited. The Trust therefore had the responsibility to clarify anomalies in its relationship with voluntary sector organisations, and to identify ways to address them; establish a clear, transparent and effective working relationship with the voluntary sector; define how voluntary sector organisations may enter into relationship and contracts with the Trust and retain their independence; develop best practice in working relationships between the Trust and voluntary organisations, and finally to define effective ways to sustain volunteers' involvement in the Trust.

The voluntary sector organisations have long been in public service delivery. The most frequently cited example is the $18^{\text {th }}$ century Coram Family or the Foundling Hospital [41] as it was then called. It received contracts from the Treasury in the 1760s to expand its role in caring for poor children in London. It is widely recognised that many of those activities now classed as public services were originally established by charities or voluntary organisations to meet needs of society not yet filled by public services or provided by state owned organisations. More recently voluntary organisations have continued to do the same and fill perceived gaps in the provision of social services. Many of the original voluntary sector or charitable services subsequently became public services as the state expanded its role in welfare provision, and either nationalised these services, or agreed that the charitable organisations provide those services but be supported through contracts or Service Level Agreements (SLAs) [23].

In recent times, various organisations have come to fulfil various health and social care roles. There are no clear boundaries to such organisations. Making sense of the variety and of the connections between different organisations and the NHS is a complex task. One way to demarcate the boundary is to define similar groups on the basis of their size, activities or area of work and then classify similar groups in different segment of the sector. Another way relates to the reasons the NHS works with voluntary sector organisations. There seem to be two:

1. The consultation and involvement of voluntary sector organisations as representatives of the views of the users, carers or the public, advocates;

2. The development and delivery of public services within the voluntary sector.

In the context of consultation and involvement, it is possible to distinguish three segments in the sector:

a) Organisations are routinely informed and invited to comment, in open consultation, on the Trust's activities. This includes all voluntary and community organisations with an interest or interface with local health and social care services. b) Organisations are routinely consulted and involved, through targeted invitations, concerning particular services or localities. This includes those listed in Care Plans and those providing services under a service level or partnership agreement.

c) Organisations are also routinely involved in business and strategic planning and review processes. This includes major or specialised service providers and those formally representing the interests of users' carers.

In the development and delivery of services, three segments broadly overlap with those defined above:

a) Organisations with an impact on mental health services, but which will probably not deliver services on behalf of (or under a service level agreement with) the Trust.

b) Organisations that deliver small scale and local services on behalf of, and under agreement with, the Trust.

c) Organisations that deliver large or highly specialised services on behalf of, and under a detailed contractual or services level agreement with, the Trust.

These three segments overlap and define practical frameworks for the Trust's approach to its relationship with voluntary and community organisations. I will now look at the relationship between the NHS Trust (LPFT) and the voluntary sector organisations.

\section{Relation between the NHS Trust (LPFT) and the Voluntary Sector Organisations}

Relationships between Voluntary organisations and the NHS Trusts tend to be specific to services, clinical areas or tasks. Most often the relationships are controlled by the NHS and follow the health service agenda of the government. The encouragement to the NHS to consult and involve patients and the public has stimulated the development of broader patterns of contact with voluntary organisations. However, in practice there is no easy or single solution or route to forge effective relationships. The structure and collaborative systems in the relationship between the NHS Trusts and voluntary sector organisations need to be based on issues such as: The variety and complexity of voluntary organisations; Local circumstances; The responsibilities and independence of both NHS Trust (LPFT) and Voluntary Sector organisations; The need for the NHS staff to appreciate voluntary organisations and their way of delivering service; and Voluntary organisations need to appreciate the NHS Trust's (LPFT) methods of delivery.

The Trust's (LPFT) and Voluntary organisations' role is to initiate partnership between a range of voluntary and statutory organisations to deliver services. The Trust (LPFT) is a form of public sector organisation operating within partnership regulations (defined in the Health Act 1999 and subsequent updates) and responding to a public sector 
agenda that includes: Government expectations and requirements of NHS 'modernisation; The best value approach to Local Authority services; Revised guidance on the Care Programme Approach; The 'Valuing People' agenda; The agenda for patient and public involvement in the NHS; The 'Essence of Care' agenda; Government commitment to establishing how statutory and voluntary organisation can develop a coherent, shared strategy to modernise the sector's capacity to deliver effective services; The development of 'community planning' through Local Strategic Partnerships (LSPs) and the involvement of voluntary and community groups).

This environment poses a challenging agenda for the Trust and voluntary organisations, particularly as current relationships are largely related to past practices and structures (in predecessor NHS Trust and Lincolnshire Social Services), where there are inconsistencies between health and social care which do not fulfil the Government's agenda for the voluntary sector's involvement and delivery in public services. Again, voluntary organisations that deliver public health and social care services are expected to remain independent and separate from NHS Trust or Local Authorities that fund or otherwise support their services.

A range of structural problems and resource constraints in the voluntary sector, and an apparent misconception of voluntary organisations' staff being unskilled among statutory organisations, limit the potential of some voluntary organisations to deliver public services. The government has recognised this and a national development fund aimed to build the capacity of the voluntary sector and modernise its way of working was established [36]. At the same time, the NHS and Local Authorities were encouraged to fund the services provided by voluntary organisations within their localities. In Lincolnshire, the recognition of these issues by local authorities and voluntary organisations led to a focus on finding ways of extending the capacity of voluntary organisations.

These developments suggest the question why should statutory institutions encourage the voluntary organisations to be involved in public service delivery and why would voluntary organisations want to provide public services? Statutory organisations with a positive attitude to voluntary organisations may assume the sector can bring new or different skills to a particular service, and that the sector may be closer to the community than the state institution and therefore in a better position to ensure that a particular service meets the needs of the users. Statutory providers with less positive attitudes to the voluntary sector may assume that it is a cheaper option, and that as a result either cost savings can be made, or increased capacity can be achieved for the same level of resources.

Voluntary organisations may choose to deliver public services for a variety of reasons. It may be to fill a gap that neither the public nor private sector want or is able to fill; it may be as an alternative to services that are available in the private or public sector, but which the voluntary sector considers to be of poor quality, or unsuited to the needs of those who use the service; it may be simply to offer choice to service users - a service provided in a different way.

It could be argued that a successful voluntary organisation is one that sees a need for a service develops a way to fill the need and operates it effectively and efficiently. However, when the service becomes a general need and of concern to the public, statutory agencies tend to take over to expand the service. However, despite the existing expertise in the voluntary sector, once the state takes over the service, it often pays no attention or makes little reference to the experiences or expertise of the voluntary organisations that initiated the service originally and developed it. This suggests a waste of experience and talent. Clearly, where this occurs, it may lead to problems.

In UK, the government's policy on community care services was strongly developed with the third sector in mind. This is evidenced in the Community Care Act [19], which embraces the full involvement of the third sector in mental health care services in particular. Despite this policy, however, the collaboration between the statutory and the voluntary organisations to improve the quality of the service is weak [59] and problematic, [3]. The weakness of this collaboration has been attributed to a lack of understanding of each of the other's objectives, missions or vision and organisational practices, methods and significantly, difference in respect of their structures, resources [67] and their value systems [48]. There is also an issue of confidence and trust by the professionals of the formal sector about the capabilities of semi-skilled personnel of the third sector. Some professionals even see any sharing of skills, knowledge and experiences with the non-professional as a threat to their profession [34]. This is again evident by research by [9] who realised that half of the Third Sector organisations surveyed in London had negative experiences from statutory services agents. The formal organisations tend to be rigid and inflexible (bureaucratic) while third sector organisations are flexible in dealing with the provision of the services they deliver. It is clear that there are issues of discourses between the Third Sector and statutory organisations in terms of how to improve the quality of services in the mental healthcare. Researchers /academics have tried to resolve problems associated with discourses among actors of mental healthcare system by developing models, this, however, has not achieved the desired results. This paper proposes another model which may achieve the expected desire. The model proposing is designed to identify criteria to achieve 'complete collective satisfaction'. 'Complete collective satisfaction' is the state where through a process of collaboration, discussion, negotiation, sharing and compromising all individual stakeholders' attached interests, ideas, needs, aims etc. are detached from individuality into collective set of goal or interest or meaning based on all-inclusive satisfaction.

At the collective level, all the stakeholders agree on what it means to achieve high quality of service or service to 
service users being classified as highest quality. 'Complete collective satisfaction' is the point where collective agreement of the stakeholders of what quality of service delivered is, is achieved. There are different types and levels of satisfaction for different groups of people, though some may be shared. Service users' satisfaction is about integration into the community as well as about employment, housing, timely delivery etc. Government or taxpayers' satisfaction is about cost-effectiveness. Accredited agencies' satisfaction is the percentage of persons discharged from hospitals followed up with community services within days. Providers' satisfaction may be the cost-effectiveness and efficiency of their services, the availability of resources, the number of service users making informed decisions and being self organised, independent, socialised within their community. Public, families', neighbours', carers' satisfaction is that service users become independent in their communities and find some form of employment and that the rights of service users, their families and carers are respected. These are some of the indicators used to evaluate the quality of the service from the perspective of the various stakeholders. When all indicators signify a high level of satisfaction (desirable) and when their values do not depend on who is a member of their collective, then one can say that a 'complete collective satisfaction' has been achieved through the support provided by the mental health care system.

In the present study it has been considered advantageous to consider what helps to provide and maintain highest quality mental health care delivery as a system (and thereby helps to avoid wicked problems when changes introduced into the system are studied, see section on avoiding wicked problems). This makes it possible (and necessary) to consider what produces behaviours as well as what the behaviours include. It also makes it possible to clearly identify its structure (i.e. what links its components, including its interactions) as well as which components may be changed to induce change (in the way of the 'gates') and how changes may be controlled.

Figure 1 summarises some of the mental health care system's aspects such as the structure, the interdependence and interconnections of the components (sub-systems). The components within the system are referred to as "insiders" (They are referred to all actors that have direct input or directly affected by the mental healthcare delivery systems' activities) and those outside the system, in the environment are the "outsiders" (They are referred to mainly policy makers, the Government and other actors who are not directly affected or involved in the service delivery of the mental healthcare, see figure 1). All the components of the system have roles they play together to ensure efficiency and effectiveness of the system, its resources and functioning. The mental health care units in hospitals play mainly medical roles. Social services departments and other social service providers handle the social issues of the mental patients, e.g. stigmatisation, employment, socialisation, independent living etc. The care providers, the patients' advocates, the Lincolnshire Partnership Foundation Trust and the voluntary sector organisations all play a role in the provision of mental health care services. These and other components of the system have to work together and their contributions depend on each other as part of the system's performance and survival.

However, what is missing in these interdependence and interconnection of roles and performance is collaboration via communication [13]. Communication (collaboration) seems not to be in existence, and where it exists, it is very limited e.g. the communication between the NHS Trusts (LPFT) and voluntary sector organisations despite government white paper encouraging them to collaborate [ibid]. 


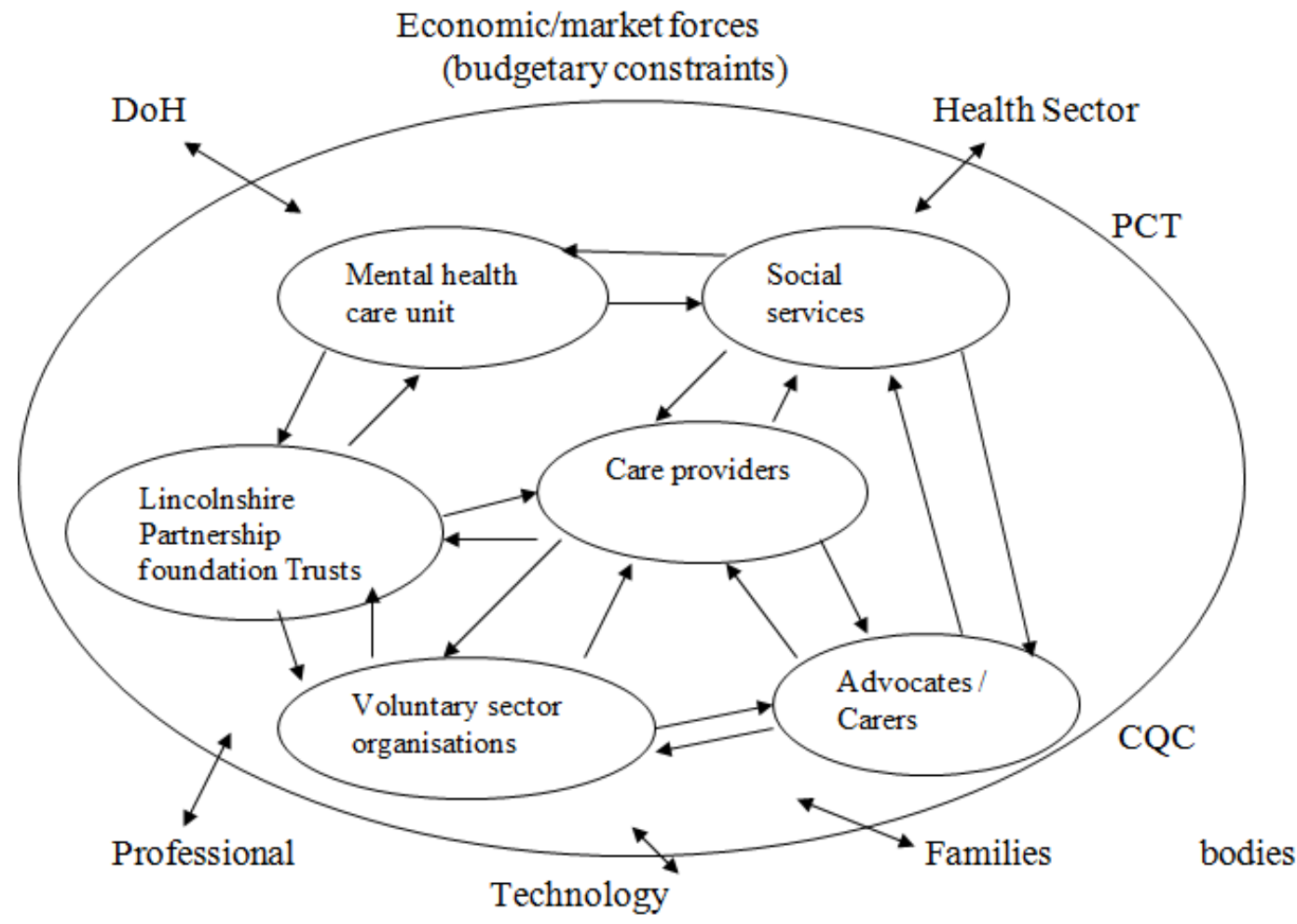

Pressure groups/media Legislation

Key

: Links in terms of political or economic roles, functions or flow of information or resources, and responsibilities and accountability.

Overlapping links in terms of political or economic roles, functions, or flow of information or resources, and responsibilities and accountability.

Figure 1. Actors within and outside the Mental Health System

\section{Mental Health Care Delivery System}

In qualitative research, one of the issues is how to explore the meaning that actors bring and generate within social interactions. However, in most research on mental health care services, the concentration had been on the inputs of the strong actors, namely the government, the NHS and somehow some voluntary organisations, with less attention on the weaker actors like service users, the family or relatives, carers and advocates. This paper focuses not only on moving the 'gear' to higher level of service users controlled and emancipatory approach to service delivery but to the level of dialogism where all stakeholders are involved in collaboration.

The state through its agent, the NHS, is responsible for ensuring that the health needs of the citizenry is adequately met. The government, therefore, provides the resources in terms of equipment, facilities and personnel needed for the delivery of health services to the citizens, the patients. The government in the process of resourcing the NHS sets targets through the Department of Health, like cutting down of waiting times, increasing the numbers of surgeries undertaken per hospital per month and other issues. But for the health care system to be effective in its performance or improvement in its performance in terms of meeting the local needs and expectations, it may be necessary to incorporate the inputs of the clients, the patients. However, to some clients interviewed in Lincolnshire, the system is not performing the way it should, they argued that some of their colleagues after their medical treatment had to go back to the hospital because the 'system' has not made provision for their for social integration and social needs particularly the mental health patients. It is being argued that where such provisions exist, the government decides what is needed and the criteria for measuring the performance without considering local needs of the citizens, which may be different from one locality to another. The clients (patients) claimed that where the system seems to give attention to their needs, the government thinks the system is not performing because of its criteria for performance improvement is different from that of the patients and, therefore, closes down such hospitals or departments in the hospitals even when the citizens protest.

It is being argued that mainstream mental health care research tend to be clinically dominated, reflecting the linear and hierarchical approaches of medical professionals who 
based their analysis on quantitative and experimental testing with less attention to qualitative research approach. One of the focuses of the paper, therefore, is to give attention to qualitative research in mental health services by giving audience to service users, carers, the family and the community through the Actors-Dialogism-System [1].

The aim of the study is to explore how a system, Actors-Dialogism -System when employed will bring all actors of the mental health system together in collaboration and engagement to bring improvement in the quality of service delivery. In the process the study explored the relationship between the NHS and the patients in the mental health care services delivery systems. An initial research or interviews conducted indicated problem of conflict and divergent views, aims, directions and strategies of the each of the actors in the mental health care delivery system. The paper reports on how greater consensus may be achieved among the actors or the stakeholders of the service in the phase of plurality of conflict.

The government sets targets through its agents but these agents are remote from the local needs and, therefore, not able to know and provide the specifications of the clients' needs and expectations. Again other service providers or stakeholders namely, advocates, family, community, carers, social workers, GPs, Psychologists, service users are not involved in policies or strategic plans on the service. Politicians sit at Westminster and decide the faith of people with mental issues with no inputs from patients or the community. There is, therefore, the need for some form of collaboration among all interested parties of the mental health care delivery system in order to meet the needs and expectations of all including the clients.

From the interviews conducted, it could be said that the needed collaboration among the stakeholders is not happening because of communication problems and, therefore, the crisis in the NHS. There are a number of ways to resolve the problem of communication identified among the stakeholders, but the one that the paper focuses on is the possible improvement of communication in the organisation of the mental health care system. It, therefore, proposes the use of 'information overload' (dialogism) as a process to destabilise the existing communication system of the mental health care delivery system in order to increase the level of interaction among all the interested parties. It is believed that in the process of destabilizing the communication links, the resultant increase in interaction will stimulate self-organisation of the system, using the dialogism approach to achieve 'complete collective satisfaction'.

\section{Dealing with the Criticisms}

Traditionally, responses to questions on performance of public service delivery exclude the inputs or views of clients for whom the service is meant. There are indications that this may be changing, however, as studies increasingly involve clients $[64 ; 32 ; 65]$. It has been argued that the reasons why civil service organisations like the NHS are becoming ineffective is the lack of involvement of clients. Although the managers of the NHS Trusts have introduced various performance measurement procedures to evaluate and improve their services, the use of the results of the representation does not seem to 'fit' the needs, interests, aims and preferences of its clients anymore. Consequently, consecutive governments have increasingly emphasised the important roles of users and in particular those of voluntary organisations. In Lincolnshire, the latest reforms have introduced a delivery system in which the Primary Care Trust (PCT) and the Lincolnshire County Council (LCC) are to use the government's criteria for the allocation of funds in commissioning of services. This means that the Lincolnshire Partnership Foundation Trust (LPFT) and the Voluntary Sector (VS) are now able to bid for 'healthy competition'. This introduces the problem, however, that the evaluation of their services is based on targets set externally by the government, irrespective of local needs and expectations [62]. This suggests that they can be used for purposes other than those for which they are intended such as 'pushing' ideas or gaining 'political scores' rather than solving actual problems. Such dependencies imply that problems will tend to be wicked rather than tame.

Another approach that has been taken by governments to deal with the criticisms of the services for which they carry responsibility (and that have neglected the voice of the client) is to stop providing those services. This tendency has been shown to lead to what Milward [44] has termed 'the hollow state'. It implies decentralisation, privatisation and competition in the public services. This has made internal checks on their performance subject to the supervisory regulatory institutions of the state, like the Audit Commission. This development extends to voluntary sector organisations that operate as contractors to the government the 'contract culture' [2]. The unfortunate effect is that the Government attempts to manage performance of voluntary sector organisations without supporting the organisations themselves or even managing them. Examples where this happens include the areas of health, education, welfare, housing etc. It has had to devise and revise frameworks for performance management.

Lincolnshire is one of the largest counties in England in terms of area, although it is relatively sparsely populated. However, it has as many cases of mental health patients as any other county in England. When it comes to mental health care problems, the issues are reasonably the same everywhere in England. Any resolution of the mental health care problems in Lincolnshire appears reasonably applicable to any other place in England - although transferability will have to be checked as the complexity of mental healthcare and different needs of service users complicate such transferability.

Other approaches will have to be explored. Collaboration within the health sector (intra-sector collaboration) and with other sectors (inter-sector collaboration, for example with 
the third and private sectors, etc.) appears fundamental. This applies to mental health care agencies such as the Lincolnshire Partnership Foundation Trust (LPFT), the Lincolnshire County Council (LCC), the Primary Care Trust (PCT) and the Lincoln Hospital. They need to establish information networks to share information and resources and to encourage other actors (such as agencies outside the health sector) to participate in the mental health service delivery system. It has to be explored to what extent these changes have a sufficiently large number of 'gates' (areas where change may be implemented) - so as to avoid the emergence of wicked problems. There are many such 'gates', but not all of them will lead to the solution of tame problems (problems which can be solved without unintended side-effects). The 'gates' include day centres, social network groups, domiciliary support centres, case management efforts, supported employment programmes, employment workshops, drop-in-centres, etc. Improvements in each of them may destroy those in others so nothing is changed.

\section{Avoiding Wicked Problems}

This kind of accumulation of improvements in each set of possible gate or route to the solution of the research problem seems possible only through collaboration among the stakeholders, right to the point of delivery. Collaboration serves as a means for all stakeholders to share information across actors and stakeholders and to build a common understanding of what high quality service implies, i.e. achieve 'complete collective satisfaction'. At the collective level, all the stakeholders agree on what it means to achieve high quality of service to service users being classified as highest quality. 'Complete collective satisfaction' is the point where collective agreement of the stakeholders of what quality of service delivered is, is achieved. There are different types and levels of satisfaction for different groups of people, though some may be shared. Service users' satisfaction is about integration into the community as well as about employment, housing, timely delivery of service etc. Government or taxpayers' satisfaction is about cost-effectiveness. Accredited agencies' satisfaction is the percentage of persons discharged from hospitals followed up with community services within days. Providers' satisfaction may be the cost-effectiveness and efficiency of their services, the availability of resources, the number of service users making informed decisions and being self organised, independent, socialised to form an integral part of their community. Public, families', neighbours', carers' satisfaction is that service users become independent in their communities and find some form of employment and that the rights of service users, their families and carers are respected. These are some of the indicators used to evaluate the quality of the service from the perspective of the various stakeholders. When all indicators signify a high level of satisfaction (desirable) and when their values do not depend on who is a member of their collective, then one can say that a 'complete collective satisfaction' has been achieved through the support provided by the mental health care system. Now let turn to the research problem which improvement in each set of gate seek to solved as referred above and the consequent research questions.

\section{Research Problem and Consequent Research Questions}

It has been argued in the above that there are a number of difficulties in the way the NHS and the Voluntary Section attempt to complement each other - in particular in the mental health service area. A number of reasons have been identified, for example the historical development of both types of organisations. It would seem that some of the difficulties cannot be solved on one level, for example by changing the agreed upon task of the NHS. It has been argued that another approach is appropriate, one that links various organisational levels. The difficulties can be seen as arising from a lack of communication between the statutory agencies of government and voluntary sector organisations [13]. The study reported here has been designed to explore this lack and to identify in terms of performance measurement how communication between the management of the NHS Trust and management of the voluntary sector organisations can be improved. It appears important to add that not only is the communication between the NHS Trust (LPFT) and the voluntary sector organisations limited, but also communication between the Trusts and users of the services, and other service providers.

The way forward for improving communication appears to be, as argued, through changes in the collaborative efforts of all the components (actors) of the mental health care system. This has been the focus of the paper. Its starting point consisted of a series of criticisms of the way the NHS functions. This has led to an analysis of the reasons for the criticisms in the light of the claims of the NHS that it is able and willing to improve. It was concluded that the criticisms refer to the side effects that appear to be direct result of a number of government intervention, among them the instruction to achieve targets or criteria in line with the use of the Balanced Scorecard (BSC). This makes the criteria for performance improvement not internally generated but externally determined. Trying to implement this instruction has led to unintended negative side effects, which are the reasons for the criticisms.

One such side effect is that the professional healthcare workers have adopted the criteria and therefore work purposely to meet the criteria with less attention to what is morally or ethically required of them than one might expect. This means that the NHS professionals, in order to satisfy the criteria of the BSC and similar performance measurements (tick the boxes), have had their attention and energy diverted from important moral and ethical issues relevant to the improvement of the quality of services the government is 
aiming at. Another side effect of implementing improved performance delivery is the criteria or target model instituted in NHS. This seemed to have prevented other key actors of the system from participating, engaging and contributing their quota to the performance improvement of the mental healthcare service delivery.

Studies like the present one may be designed in a number of ways. One is to delineate what such a study intends to achieve, given what type of area. This usually is summarised as the formulation of a research question. This approach will be followed in the present text as well. The research question is: where do the NHS Trusts fail in relation to the Voluntary Sector and what can they and/or that Sector do to improve the situation and create a better service delivery system for mental health support? There are of course additional or sub-questions that have to be answered to make it possible to answer the research question. They relate to practical issues such as how to make performance and hence possible improvements visible (e.g. what is the logic of the concept of performance; $[37 ; 39 ; 25 ; 27 ; 28 ; 4 ; 51 ; 50 ; 57]$ identify the relation between performance and the criticisms and determine what would the organisations involved need to do (or have done to them) to maintain the improvements and even to strive for further performance improvement.

\section{Design Considerations}

Answering a research question requires a plan, or as it is usually called, a research design. It is easy to start running in circles and not produce anything. The plan identifies a number of steps. The first is to look for a framework, i.e. a set of general ideas on where the answer to the research question may be found. A second step is to find elements within the framework that together answer the question. A third is to argue that the first two steps do lead to where one wants to go. This step tends to be the most difficult to take. One must not only be aware of what happens in the first two steps, but also have access to some way of evaluating and correcting to continue in the right (chosen) direction.

The framework chosen to answer the research question of this study (as a way to avoid the risk of wicked problems) is that of conglomerations of components (humans, employees, volunteers) that are linked via the constraints of interaction to achieve some objective or task. Such conglomerations tended to be referred to as systems for more than five decades - partly due to the work of organisations like the United Kingdom Systems Society. This might suggest that the work done within the framework is part of systems research. It is not - although the author has freely borrowed concepts and ideas from that type of research. Its focus is the way individuals (humans, departments, clients) create the resources to achieve collective tasks (including their interactions with other individuals or groups of individuals), not the way systems may serve as the goal-dependent objects of research [61]. One consequence of this focus is that the work can be characterised as qualitative in the way that is popular in the literature [29]. In other words, whatever is to be made visible or measured is context-dependent. In the case of components the context is to be seen as other components, in the case of systems as those activities of components that are not part of the interactions as well as any changes in their environments that influence the activities of the systems involved.

In the second step there are a number of alternatives as well (given the framework chosen). One is to search for feedback mechanisms between the NHS and any of its clients - as a way to assess what is happening and what may or should happen. The organisation should know for example, when it is too slow to deal with clients' problems. Another design is to search for those points in an organisation, the change of which has large innovative effects, e.g. in the direction of becoming more client-sensitive. A third possibility is to look at the way individuals in the organisation become aware of its overall functioning, as well as of their own contributions (e.g. via internal assessment forms).

A fourth possibility, and the one chosen in this study, is to explore the relation between the NHS and a particular client i.e. the voluntary sector. Considering the latter as a client of the NHS may appear like taking a leap of faith. Still, its members are like clients in that they often provide services, especially to ex-clients of the NHS, i.e. to those it returns to society like people with mental health problems. Members are also like clients in that they are 'horizontally' organised, i.e. without an overall plan of their own or a clear distribution of labour. Again, similar to what may happen to patients, the NHS appears intent on imposing its own ideas (e.g. what services to provide, what treatments to follow). At least, this is what it has been criticised for - partly in principle, partly because this appears to influence its performance negatively.

The various mission statements share a focus on the curative model, the medical model. It tends to 'medicalise' all mental health patients, i.e. treat them as ill and as to be brought back to an original and healthy state. This seems problematic. A patient with a broken leg can have it fixed and healed to the state it was in before it got broken. However, the same cannot be said of a mental health patient. Sometimes they may only need medical attention; sometimes they may need other things, for example to cope with issues of social stigmatisation, pressures, being shunned in one's community. Various authors have expressed critical concerns over the 'medicalisation' of mental health patients $[50 ; 57]$. Their problem is that many mental health patients may only have behavioural issues that make them deviate from the cultural 'norm'. Bringing them to this norm would not constitute a cure, therefore. This is where the relation with the Voluntary Sector often is strained. Its focus differs from that of the NHS, i.e. it has a behavioural one. People are not like machines that can be repaired and made to function again [68]. They have to be supported to develop a role that fits their social environment. There is no general role. For example, being a member of a social group makes it easier to access other groups, to survive socially (and even to build up 
stronger physical immune systems to various diseases). Organisations in the voluntary sector provide many services of this kind - for example supporting people with sudden losses (deaths, marriages), facilitating social interaction and helping with finding jobs. Such services do not always lend themselves easily to a quick evaluation. Their 'social model' focuses on disabilities in fully participating in mainstream social, attitudinal and economic activities. It asserts that society and social organs have to recognise and celebrate the differences among the people rather than make them 'normal' by homogenising them. The difference between the medical and social models does not necessarily lead to bad results. They are due only to the expectation that one model should fit all. Improvements in the tasks of the NHS and the Voluntary Sector require cooperation, therefore, rather than domination.

Recognising this principle, the Government did initiate a review that set out the Government's vision of how the NHS and the Voluntary Sector should work together as equal partners to bring improvement to the public services [13]. However, no clear results seem to have been achieved yet, although there are some clear advantages to such cooperation. Among them is the fact that the voluntary sector is more cost effective. It is also more sensitive to the future role of clients and to their long-term needs. Its added value is complementary to that of the NHS, therefore. People with mental health problems often prefer help, moreover, from the voluntary sector to prevent stigmatisation. Co-operation also may contribute to the stimulation of cultural life, one of the aims shared by the NHS and the voluntary sector.

It is expected that the study will contribute in more than one way. On one level, it will be possible to explore, identify and demonstrate whether and how poor relationships between the NHS and the voluntary sector organisations arise and may be dealt with. On another level, it will be possible to gain (some) knowledge of the roles and functions of a particular type of organisation, a state organisation. On a third level, a new model of performance improvement model may have to be proposed which takes care of the shortcomings of the existing forms of cooperation [49].

\section{Research Methods}

A phenomenological method will be used in this research because it is one of the methods which help to understand issues or situation from the perspectives of the people involved in the situation directly or indirectly. Phenomenology as a concept can be looked at as a research philosophy, but also as a research method for gathering and analysing data [33]. As a method, phenomenology allows for the discovering of peoples 'world view', thus capturing actors' or persons' involved subjective experiences and views of the situation or on the issues. In human interactive situation like the mental healthcare service delivery, it helps to appropriate in-depth information and perspectives through qualitative methods of interviews and focus group discussions.

The methods of data collection were semi-structure interviews, focus group discussions and secondary data from some the actors' involved in the mental health system. The participants were, one from the Lincoln County Council (LCC), one from the Primary Care Trust (PCT), three from the Lincoln Hospital (social services unit), and six from the Lincolnshire Partnership Foundation Trust (LPFT) and seven from five voluntary organisations in Lincolnshire were interviewed. This was after ethical forms from NHS Trust had been completed and letter of introduction and consents forms sent to the managers had been accepted and returned. Due to the busy schedules of some of the managers particularly the NHS Trust managers, the researcher has to adopt a ice ball rolling method to get access to the managers and other respondents, that is each respondent the researcher finished interviewing was nicely asked to link or connect the researcher to the next relevant manager for interview (through telephone call or physically took the researcher and introduced to next relevant manager) for the next appointment to be arranged or interviewed where it was possible. Sometimes the researcher met some of the respondents after their working hour because of their busy schedule. In addition two focus group discussions were conducted, in The Mind (voluntary organisation) in Lincoln and the other the same Mind but this time in Grantham. For the focus group discussion, the participants were not managers but Trustees (Service users who had somehow recovered from their mental illness and live an independent live with no support or very limited support.

In all a total of eighteen managers and directors were interviewed form the Lincolnshire County Council (LCC), Lincolnshire Primary Care Trust (PCT), Lincoln Hospital, Lincolnshire Partnership Trust (LPT) and some voluntary organisations like Lincoln Mind, South Lincolnshire Mind, RETHINK, Speaking Up, and the Pelican Trust. These interviews were recorded on audio cassettes and later transcribed into text. These texts were analysed by the researcher using descriptive coding, interpretative coding and pattern coding system to identify the emerging themes from the interviews. The following themes emerged from the coding and the analysis, namely, state control of the mental health care system, organisational culture: professionalism, performance service delivery: continuous process, service users' needs and expectations, and participatory communication: empowerment and collaboration.

An inductive qualitative technique was employed for the data analysis. Data were coded as the research develops and themes and concepts generated as they emerged [43]. The process of analysing the research data consisted of three concurrent flows of activities, namely, data reduction, data display and conclusion/verification. The purpose of the data reduction and data display was to facilitate logical and concurrent drawing of conclusions [ibid]. Conclusions were in the form of momes leading to the formulation of propositions and generation of themes, drawn and verified from the data collected and the literature. Data reduction and 
data display refer to the process of selecting, simplifying, abstracting and transforming the data collected. The analysis process for the research started with the writing of the contact summary sheets (reflection of the interviews), transcription of the recorded interviews on tapes into text, coding, teasing out commonalities and differences in responses to the same questions, creating clusters and partitions, memos and propositions, leading to the generation of themes. The whole process of data reduction and display have been diagrammatically represented in the diagram below in figure 2

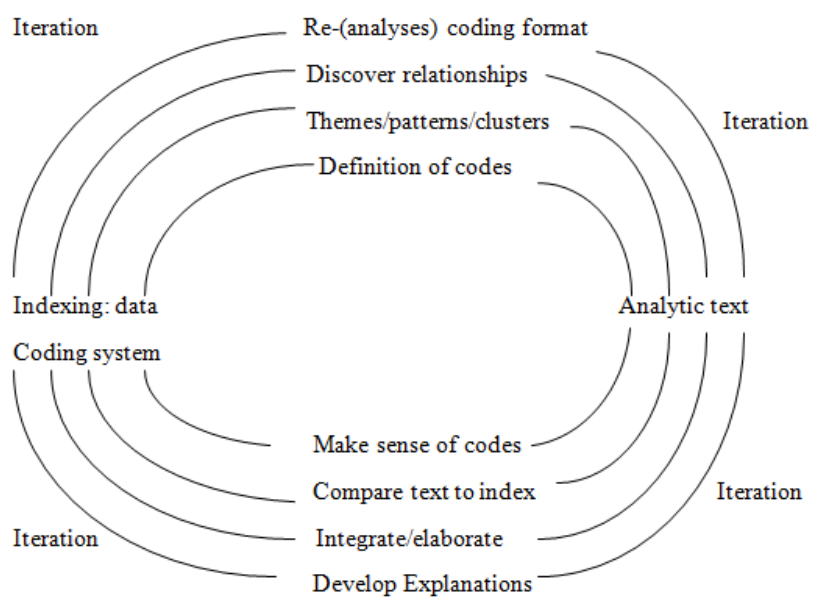

Figure 2. The processes of analysing the data collected.

\section{System Complexity: Dialogism}

One issue of interest to this research is the emotive-ethical responsibilities of fully- recovered mental health patients (like the Trustees of the South Lincolnshire Mind), families or carers to other mental health patients who are not in the position to tell their stories. It is in such situations that carers, parents, friends and other stakeholders like voluntary organisations cannot afford to be bystanders, but have an emotive-ethical obligation to act, to intervene; that is moving from the position of being spectators to participants. 'This is what Bakhtin calls our in-the-moment answerability'. 'Answerability' is the responses or reactions to a compelling story told or heard from others that tugs emotional passion, outrage, and invites stakeholders' capacity to act, to help, to do something for someone. Therefore there are circumstances in an organisation or in society where people will engage in emotion, and make an ethical judgement, in-the-moment. The study, using storytelling as a facilitatory system, therefore explores how 'emotive ethical' sense making story, which is in-the now, is used to address a question of how patients/public will act through storytelling to change what is happening to others, friends or even for themselves in order not to return to the old situation of mental illness. The emotive-ethical sense making therefore prompts moments of reflexivity; 'we are the only people who have to act to bring changes, if we do not do it, no one will do it'.

In business language, dialogism is when people with different logics meet in the same time and place, and engage in something transcendental, on their differences, allowing for a possibility of something generative to happen, out of their explorations. 'In a broader scope, dialogism is different in how different stakeholders hold firms accountable for the stories they tell. It is definitely not about consensus, nor is about some actors trying to sway people to accept their 'point-of-view' of logic. In a best case scenario, it is a new way of viewing how all the logics interrelate to emerge. It is more about learning to listen at a deep level of reflexivity, than it is about arguing to make one's story the story of a group.

Dialogism is not the same as having a dialogue. Dialogue in business is about persuading, or facilitating consensus. The dialogism (polypi) of storytelling organisations as per this study is a coordination system. The notion of dialogue in business or organisation, as stated, is persuasive in nature or a consensus facilitation process. It usually involves a hierarchical or linear relationship between actors or parties with imbalance power dynamics. In terms of systems perspectives as described earlier, it is an input/output system relationship or even opens system relationship where the dominant actor detects the nature of the relationship and the direction.

The researcher's strategy is to move away from input/output and open system thinking, as a way of controlling and measuring performance of the mental health care system (linear and hierarchical) to a complexity system thinking which is in line with Edgar Morin's [45] idea of system thinking. He defines his system as "dialogical relationship ... between order, disorder and organisation, that is 'antagonistic' concurrent and complementary" [47].

It therefore means that the flaws of linear and hierarchic system thinking can be overcome by the use of holographic combinations of complexity. Morin's dialogic and holographic properties, together with recursion, have the possibility of getting rid of the hierarchic order element. We are in an era where the mental health care system is perceived as 'floating' not fixed. This is because the data collected and the findings gathered indicate that the interests, needs and expectations of the stakeholders will always float with time. The components of the mental health care system will always float with time and therefore its components' interests, needs and expectations will accordingly change with time and space. It therefore means that the components of the mental health care system do not emerge into wholeness because the components or the organs do not emerge. The reason is that each of the components (actors) has its own specific focus, mission, objectives and interests, therefore the whole is never finalised with time and space. However, they emerge in the story they tell through holography (dialogism) to achieve the purpose of the mental health care system in a particular time and space.

Morin, like Bakhtin, used system language as a complexity. Bakhtin preferred the heteroglossia of language, 
the opposition of centripetal (centring spiral of order) and centrifugal (decentring spiral of disorder) forces of language. For Morin, the speech acts are dialogic in social activities of order, disorder and organisation [45; 47]. Therefore proposed three properties of complexity: dialogical, hologrammatic and recursivity.

"Dialogical" is the interplay of order, disorder, and organisation, which is antagonistic, concurrent, and complementary. Morin's argument is to go beyond open system thinking because it is wholly insufficient when applied to living or social systems [45]. Morin [47] explained: 'at the birth of the universe, there was an orderly, disorder and organisation. Dialogic triggers off by calorific turbulence (discord) in which under certain conditions (random encounters) organising principles made possible the creation of nuclei atoms, galaxies and stars'. In the same way dialogical (order/disorder/organisation) auto produces self-organisation in the physical, biological and human worlds. The same principle of dialogism can be applicable to systems (mental health care system), where past narrative histories (retrospective), present narrative or stories and future strategy stories (prospective) can be used as 'facilitatory system' for the self-organisation and self-evolution of the mental health care system.

The holographic is where the dynamics of the whole are presented in parts, as in laser photography. Holography allows complexity properties to be non-hierarchic, and it is implicated in processes of complexity beyond open system thinking. In holography, various lenses combine to consummate dimensions without presuming hierarchic ordering. There are various ways of storytelling sense making; each of the sense makings is a way to control social interactions. Weick [66] lamented that sense making is limited only to retrospection.

Recursion is a 'dynamic and generative feedback loop' between whole and parts, where order and disorder, observer and observed are situated [45]. The recursion principle moves beyond open system theory's opposition of feedback-regulatory loop and feedback -amplification loop by situating a self-organisation (generative) loop. An e.g. of recursion is how narrative and storytelling shape systemic and systemic shapes narrative-storytelling.

The complexity theory allows for reflexivity-transcendence, as well as retrospective-prospective sense making. The emergence of this is the production or creation of global patterns of behaviour by the actors and the agents in the complex system, the mental healthcare service, to interact according to their own local rules of behaviour, without intending global patterns of behaviour that come with it. The emergence of the global patterns cannot be predicted from the local rules of behaviour that produces them; that is the patterns cannot be specified to individual behaviour [60], but on the collective, as complete collective behaviours.

The mental healthcare system as it is now is complex system, less collaborative among the actors and hierarchical and therefore makes concepts like holography which allows inclusion of non-hierarchical properties to emerge problematic. One of the problems faced by mental healthcare system is that it does not allow order and disorder to emerge to produce self organisation needed to increase the interactions and collaboration among actors of the system and therefore there need for a system or a model which takes care of the above mentioned problems and for that matter the research problem of the study. It is for this reason that the researcher has proposed a model that takes care of all these issues or features relevant to the improvement of the performance of the mental health care delivery as a way of resolving its problem, and the research problem of limited communication between the NHS Trusts (LPFT) and the voluntary sector organisations. The proposed system or model also aims at increasing the interaction, communication and collaboration among all the actors (stakeholders) of the mental health care system.

The proposed 'system' (model), the Actor-Dialogism-System [1] is a theorisation of performance improvement, which does not operate in a linear or hierarchical way like the BSC, input/output system or open system, but the 'system' operates in a complex spiral relationship dialogically. The proposed system's complexity is a shift from 'linearisation' and hierarchic levels of ideas, arguments to something holographic. The complexity is spiral in dialogical interplay of narrative-order with story-disorder, which may produce self-organisation in storytelling organisations or systems e.g. NHS Trusts or the mental health care system. The dialogism of order with disorder in acts of self-organisation was an idea of Edgar Morin [45]. He looked at issues or problems beyond hierarchic order and linear models of system thinking into complex thinking, where issues are looked at outside the rules of order into disorder; that is the system's parts do not merge into wholeness, because the parts do not merge, and the whole never seems to be finalised except in narrative imagination. The researcher uses the word 'systemicity' in the same way Boje [11] used the word systemicity to denote unmerged parts, and unfinalised non-wholeness. He defined systemicity as the dynamic unfinished, unfinalised, and unmerged, and the interactivity of complexity properties constituted by narrative- story processes. For Boje, the purpose was to challenge the 'illusion' that 'whole systems' exist because, given the focus on emergence and self organisation, organisations or systems are continually being reorganised, and never seem to finish long enough to have merged parts, a kind of fixity of wholeness.

Sense making storytelling is highly embedded in talks, in visual images, body language and in the textuality (writing). The Living story model plays a significant role in sense making storytelling, which is very relevant in the proposed system (model) for improvement in communication, increased interaction and collaboration, therefore the performance of the mental health care delivery system. Storytelling is used as a 'facilitatory system' because the researcher sees all organisations in the mental health care 
system as storytelling organisations because they can be identified or recognised by the story they tell or re-storytelling of their stories.

Relating the storytelling (narrative) and living story model (principle) to the study of mental health care system, one can argue that the medical model (like the input/output model) is a mono-logic - linear narrative with Beginning- Middle- End. The NHS Trusts depend on its professionals (skills and training) to diagnose a mental problem and to prescribe a course of action (medication) believed to heal or cure the individual completely to become who he or she was before the mental condition. The voluntary organisations function like an open system, taking issues from the environment on board in their mode of operation (social model). The voluntary organisations therefore use ante-narratives, fragments of stories from service users, families, care plans, friends, carers, social service departments, NHS Trusts, etc. to build the picture of a problem and to develop the best methods to resolve the problem. What is absent in both models is the weaving elements of living stories which bring narrative and ante-narrative together in dialogue of 'polypi' dialogism via the proposed model, Actors-Dialogism-System to discuss, share, negotiate and compromise through self-organisation and self-evolving function towards achieving 'complete collective satisfaction'. It takes into consideration the interests and input of all the key actors. By this process, the Actors-Dialogism-System helps to resolve the research problem of limited communication between the LPFT and the Third Sector organisations and the communication among all the other actors. Improvement in communication by increasing interaction among the actors via the Actors-Dialogism-System will mean collaboration by all interested groups, and therefore improvement in performance of the mental health care system, this is because all including the service users' needs and input will have been considered and been part of the whole process of service delivery.

\section{Conclusions}

In conclusion, therefore, the best possible solution to the research problem will be through a dialogism process to improve performance of service delivery through increase in the interaction among the actors, particularly between the LPFT and the Third Sector organisations. It is believed that this process of dialogism will result in the 'Third Cybernetics' revolution. The Third Cybernetics revolution, which involves a movement of higher levels of abstraction of 'polypi' dialogism, from the theory of the Shannon and Weaver [58] information processing theory (sender-receiver feedback loop) model, which had been in vogue even before Von Bertalanffy's [61] general system theory; through the First Cybernetic revolution which is mechanistic, cybernetics of deviation-counter-action, that is input/output system of feedback and feed-forward loops; to the Second
Cybernetic revolution which is an open system narrative of deviation-amplification. The flaws of the Second Cybernetics revolution is that, it ignores images, or symbols, inter-textuality, multi-story dialogical and storytelling variety of human social interactions. The proposed model, 'Third Cybernetic theory' takes on board some of the flaws of the Second Cybernetics model. The Actors-Dialogism-System (the proposed) is a process of dialogism. It has four dialogisms which are co-ordinated by a fifth dialogism, the Polypi dialogism. These dialogisms are not ordered hierarchically to fall into the criticisms of open systems thinking, but are in spiral relationships of dialogism.

By applying this notion of cybernetics to mental health care, delivery is assumed to be a system with different components, some of the components (actors) are inside (insiders) the system while others are outside (outsiders) in the environment. The decision makers, the providers of the service and the mental health care service, can be conceived as operationally distinct from the service users. In the dialogism process of mental health care service provision, there is a continuous interaction between those responsible for the provision and delivery of the services (i.e. the 'outsiders/providers) and those within the system (the 'insiders'/users). These actors, the 'insiders' and the 'outsiders' ensure that the service is available, accessible, useful, being properly used, has the desired effects, and has less or no serious negative side effects. In situations where in the creation (provision) of a service, one cannot be able to distinguish operationally between the providers from the service users, then the service users are likely to be a part of the continuous production process itself. In such situations the service users might be seen simultaneously as part of the producers and therefore co-producers. In this case, the 'insiders'/service users would have to play the roles of the 'outsiders'/producers as well. In the same vein, people who are outside the mental health care system by virtue of being sound, healthy or 'normal' citizens may become part of the system (insiders) with time because of may be age, have stress at work, be depressed or have childbirth complications etc. In these situations citizens outside the system 'outsiders' will become 'insiders'.

The new role of the 'outsiders' becoming 'insiders' and therefore creators, retainers, selectors and users of the services, is perceived in the light of the fact that the researcher uses a metaphor perceiving the mental health care system as a living organism (living system). It therefore means that at any given time 'outsiders' of the system; unborn, 'normal citizens' ex-mental health patients may become 'insiders' of the system with time and space. It also means therefore that new roles might be evolved in identifying new tasks or activities such that the old roles might still contribute in the evolving process. In other words, it might involve the creation and delivery of new forms of services as per the new needs of those once 'outsiders' now become 'insiders' to produce and use the service as per their new needs. In such a situation, a living story method of 
'facilitatory system' is useful in managing the tension of re-entry from outside to inside, and then outside again. The general aim of this type of facilitatory system is to help the 'outsiders' who had become 'insiders' to become adept users of the new services, such that they can become more effective participants in creating and using the various services that might be available, irrespective of their conditions.

Consequently, there is the need for continuous interaction between the providers and the users of the services for ethical reasons and also one does not know when one will become a user of the service. This is more so in situations where sometimes the providers of services cannot be operationally distinguished from the users, i.e. where the policy makers or providers are also users and part of a continuous provisional process itself by virtue of friends, family members or the community they live in. Sometimes the service is provided by the would-be users themselves, who can become users of the service at any time taking into consideration the rate of stress levels and other work-related health problems which are in ascendancy, e.g. stress at work sometimes leads to mental health issues.

It is on the basis of these situations and argument that it is necessary that all parties (actors) of the mental health care system need to communicate, collaborate and co-produce the services in order to achieve 'complete collective satisfaction'. This may be possible through the model the Actors-Dialogism-System, which creates the enabling environment for all actors involved in the service to share ideas, information, knowledge, skills, experiences, and finally contribute and commit themselves to the process. Once all stakeholders are aware of the situation and the vulnerability of each and every one, each and every one would make the effort to ensure high quality mental health care service by communicating and collaborating with all other actors. One notion important in the interaction between the 'insiders' and 'outsiders' of the mental health care service in terms of the quality of service or the performance to meet needs and preferences of service users is the notion of inference.

For this study, the inference is the linkage of the Actors-Dialogism-System to performance improvement in mental health care delivery through the dialogism process of participatory communication. One cannot talk of inference without the notion of evidence sometimes. Evidence is the 'thing' that points to the 'other things' in the inference. In the relationship between the state (NHS Trusts) and its clients (actors), the evidence is the limited communication among the actors of the mental health care system which has affected the quality of the service. The service delivery does not meet the needs and preferences of clients, therefore to improve the quality of the service, improvement of communication among the actors is necessary in order to improve the performance of the mental health care delivery system which is based on the evidence that clients have choice and control (that is fully participating in the decision making process of the provision of the services they needed). The inference needs to be validated, that is, there should be a problem (which in the case of this research is limited communication among providers and users of the service). This problem of limited communication has affected the quality of service of mental health care, and for that matter the performance of the mental health care system. This problem needs to be solved on the basis of the evidence or what is to be inferred. The evidence intended to prove the inference validity, which includes 'testimony', a report from a source that has sufficient 'authority' [56].

In knowledge systems, evidence may be what Schum [ibid] called 'observable phenomena', that is, responses from interviews, reports from documents or expression of peoples' values, emotions, feelings etc. No single piece of evidence or report is sufficient for an inference for the purpose of 'public interest' (in such a case, the inference is considered a miracle). It is therefore important to avoid 'miracle' inferences in research of 'public interest'. This therefore suggests the need to infer from a combination of evidences necessary to validate an inference; that is, having more evidences, and deciding on which one to refer over another based on sufficient evidences. In this research, the evidences used were the observable phenomena from the interviews and the focus group discussions, observations, evidences from the literature and other reports to validate the inference, that is limited communication has affected the performance improvement of the service and therefore the quality of the mental health care delivery system. An increase in the interaction among the actors is necessary to improve interaction both at the lower and higher levels of the system's structure and communication among actors. This will lead to improvement in the quality of service and for that matter the performance of the system. In doing this, one important fact to ensure sufficient validation of the inference is the conceptual coherence of making sense of the data collected, and consequently the findings.

In a nutshell, the study identified one of the main problems behind the relatively low quality of service received by mental health patients, particularly when compared to other health patients of the healthcare service. This problem is limited communication between the NHS Trust (the LPFT) and the voluntary sector organisations, and for that matter communication among all the actors of the mental health care system. If the system is to achieve the high quality of service it is intended to, leading to improvement of performance, then this problem needs to be resolved. This problem has been identified and recognised by the government and therefore a white paper was issued asking the NHS Trusts to collaborate with the Third Sector organisations in health service provisions in general. However, this instruction from the government yielded no results, despite various health care reforms to improve the performance of the health sector.

Consequent governments implemented many measures to measure and improve performances in the health sector. One of the measures is the BSC with its Star Rating system, 
which led to financial autonomy of some NHS Trusts. Some improvement have been achieved through with the BSC, however, one element absent in the BSC is the communication among the actors and therefore this research explored the criteria for performance improvement of the services delivered and strive to develop a model which is sufficient, self organising and self-evolving to generate, an improved system (model) for quality service improvement and therefore performance that is based on increase in communication via increase in interaction among the actors. From the research, an alternative system (model) has been proposed, the Actors-Dialogism-System which intends to resolve the side effects and the problem of limited communication among actors identified with the BSC model in order to increase interaction among all the actors of the mental health care system. Improvement in communication is in the form of spiral relationships among actors. This model encourages self-organisation and self-evolution of the system and also makes the mental health care system independent of time and space. It is the belief of the researcher that the proposed model will lead to much improvement in communication through participatory communication if it is develop and organise in the ideals which is consistent with storytelling and living story theory as a facilitatory system to coordinate the processes of interaction and sharing of information, and therefore help to improve the quality of the mental health care service delivery.

\section{REFERENCES}

[1] Aggtrey, K. K. (2014) Performance Management of the NHS' Mental Health Care Service Delivery in England: The Role of the Service' Actors (Clients) Collaboration through Dialogism. Universal Journal of Industrial and Business Management, 2(7): 143-150

[2] 6, P. and Kendall, J. (1997). The Contract Culture in Public Service. Aldershot: Arena.

[3] Adams, R. (1990). Self-help, Social work and Employment. London: Macmillan

[4] Audit Commission (1999). Performance Measurement as a Tool for Modernising Government. London: The Audit Commission of the UK National Government.

[5] Audit Commission (2000). Aiming to Improve the Principles of Performance Measurement. London: The Audit Commission of the UK National Government.

[6] Bakhtin, M. M. (1981). The Dialogic Imagination: Four Essays. (Ed.) M. Holquist Austin, TX: University of Texas Press.

[7] Bakhtin, M. M. (1990). Art and Answerability (Michael Holquist and Vadim Liapunor, eds; translation and notes by Vadim Liapimov; supplement translated by Kenneth Brostrom) Austin TX: University of Texas Press.
[8] Bardhan, P .and Roemer, E. J. (1992). Market Socialism: A Case for Rejuvenation. The Journal of Economic Perspective Vol.6 (3) pp. 101-116.

[9] Bhugra, D. and La Grenade, J. (1997).Community organisations' expectations of mental health statutory services. Irish Journal of Psychological Medicine Vol.1 (14) pp. 57-59.

[10] Billis, D. and Harris, M. (1992). Taking the Strain of Change: UK local voluntary organisations enter the post-Thatcher period. Non-Profit and Voluntary Sector Quarterly 211-225.

[11] Boje, M. D. (2008). Storytelling Organisations. London: Sage.

[12] Bowl, R. (1996) Involving Service Users in Mental Health Services: Social Service Department and the National Health Service and Community Care Act1990. Journal of Mental Health Vol. 5 (3) pp. 287-304.

[13] Cabinet Office (2007). The Future Role of the Third Sector in Social and Economic Regeneration. Final Report London: HM Treasury.

[14] Cabinet Secretary and Head \& Home Civil Service (2009. Civil Service Reform, Audit Commission annual lecture. London: HM Treasury.

[15] Calnan, M. and Sanford, E. (2004) Public Trust in Health Care: The System or the Doctor? Quality and Safety in Health Care Vol.13 pp. $92-97$

[16] Daily Mail (1948). London In Helen Evans, Sixty Years On Who Cares for the NHS? Daily Mail $3^{\text {rd }}$ July 1948.

[17] Davies, C., Wetherell, M. and Barnett E. (2006) Citizens at the Centre: Deliberative Participation in Healthcare Decisions. Bristol: Policy Press.

[18] Davies, H. T. O. (1999) Falling public trust in health services: implications for accountability. Journal Health Service Res. Policy Vol. 4 (4) pp 193-4.

[19] Department of Health (1990) National Health Service and Community Care Act. London: HMSO.

[20] Department of Health (1998) Mental Health Act 1998 London: Stationery Office

[21] Department of Health (1999) Health Act 1999 London: Stationery Office

[22] Department of Health (2000) The NHS Plan. London: Department of Health.

[23] Department of Health (2000) The NHS Plan: A Plan for investment, a plan for Reform. London: Department of Health

[24] Department of Health (2001) Shifting the Balance of Power within the NHS: Securing Delivery. London: Department of Health.

[25] Department of Health (2001a) NHS Performance Indicators: A Consultation. London: Department of Health.

[26] Department of Health (2001b). NHS performance Ratings Acute Trusts. London: Department of Health. 
[27] Department of Health (2002a) Learning from Bristol; The Department of Health's Response to the Report of the Public Inquiry into Children Heart Surgery at the Bristol Royal Infirmary 1983-1995. London: Department of Health.

[28] Department of Health (2002b) Shifting the Balance of Power within the NHS: The Next Steps. London: Department of Health.

[29] Easterby-Smith, M., Thorpe, R. and Jackson, P. R. (2008) Management research: An Introduction. $3^{\text {rd }}$ ed. Los Angeles: Sage.

[30] Evans, H. (2008). Sixty Years On-Who Cares for the NHS? London: The Institute of Economic Affairs' Hobbs the Printers UK.

[31] Goodman, G. (1997) The State of the Nation: The Political Legacy of Aneurin Bevan. Ed. London: Victor Gollancz.

[32] Goodwin, I., Holmes, G., Newnes, C. and Waltho, D. (1999) A qualitative analysis of the views of in-patient mental health service users. Journal of Mental Health Vol. 8(1) pp. 43-54.

[33] Goulding, C. (1999) Consumer research, interpretive paradigms and methodological and ambiguities. European Journal of Marketing Vol. 33 (10) pp. 859-87.

[34] Gussow, Z. and Tracy, G.S. (1976) The role of self-help clubs in adaptation to chronic illness and disability. Social Science and Medicine Vol.10 pp. 407-14.

[35] Health and Social Care Act (2008) Department of Health Care Quality Commission. London: Commission Assessment Guide.

[36] House of Commons Public Administration Select Committee, HC 1209 (2008) Public Service and the Third Sector: Rhetoric and Reality. Government Response to the Committee's Eleventh Report of Session 2007-08 London.

[37] Kaplan, R. S. and Norton, D. P. (1996) The Balance Scorecard. Boston: Harvard Business School Press.

[38] Kaplan, R. S and Norton, D. P. (2000) Having Trouble with Your Strategy: Then Map It. Harvard Business Review No. September/ October pp. 167-76.

[39] Kaplan, R. S. and Norton, D. P. (2001) The Strategy Focused Organisation: How Balanced Scorecard Companies Thrive in the New Business Environment. Boston MA: Harvard Business School Press.

[40] Leug, T.T.F. (2008) Accountability to Welfare Service Users: Challenges and Responses of Service Providers. British journal of Social Work Vol. 38(3) pp 531-545.

[41] Levene, A. (2007) Childcare, Health and Mortality at the London Foundling Hospital 1741-1800; 'Left to the Mercy of the World'. London: Manchester University Press.

[42] Lincolnshire Partnership NHS Trust (2006) Annual Report. Health and Social Care Working in Partnership. UK; Bracebridge Heath Lincoln.

[43] Miles, M. B. and Huberman, A. M. (2004) Qualitative Data Analysis. (2nd ed.) London: Sage Publication

[44] Milward, H. (1994) Nonprofit Contracting and the Hollow State. Public administration Review 54 (No 1).
[45] Morin, E. (1992a). From the concept of system to the paradigm of complexity. Journal of Social and Evolutionary Systems, 15(4), 371-385.

[46] Morin, E. (1996) A New Way of Thinking. UNESCO Courier, February, pp 10-14.

[47] Mosher, L.R. and Burti, L. (1994). Community Mental Health: Principles and Practice. New York: W. W. Norton \& Co.

[48] O’Hear, A. (1980) Karl Popper. London: Routledge.

[49] Oliver, M. (1990) The Politics of Disablement. Basingstoke London: Macmillan.

[50] Radnor, Z. and Lovell, B. (2003) Success Factors for Implementation of the Balanced Scorecard in a NHS Multi-agency setting. International Journal of Medical Marketing Vol. 3 (3) pp 174-188.

[51] Resnick, S. and Wolff, R. Knowledge and Class: A Marxian Critique of Political Economy. Chicago; University of Chicago Press.

[52] Rintala, M. (2003) Creating the National Health Service, Aneurin Bevan and the Medical Lords. London: Frank Cass Publisher.

[53] Rivett, G. C. (1998) From Cradle to Grave: Fifty years of the NHS. London: King's Fund.

[54] Rothbard, N. M. (2000) Egalitarianism as a Revolt against Nature and Other Essays. $2^{\text {nd }} E d$. The Ludwig von Mises Institute Alabama: Auburn

[55] Rowe, R. and Calnan, M. (2006) Trust Relations in Health Care: Delivery a Theoretical Framework for the "new" NHS. Journal of Health Organisation and Management Vol. (5) pp 376-396.

[56] Schum, D. A. (1994) The Evidential Foundations Probabilistic Reasoning. $1^{\text {st }}$ Ed. New York: John Wiley Sons.

[57] Shakespeare T. (1996) Disability, identity and difference. In C. Barnes and G. Mercer (eds.) Exploring the Divide: Illness and Disability, Leeds: the Disability Press.

[58] Shannon, C. E. and Weaver, W. (1949) The Mathematical theory of communication. Urbana: The University of Illinois Press.

[59] Simpson, R. G. (1996) Relationship between self-help organisations and professional health-care providers. Health and Social Care in the Community Vol. 1 (4) pp 359-70.

[60] Stacey, R. D. (1996) Complexity and Creativity in Organisations. USA: Berrett Koehler

[61] Tritter, J. Q. (2009) Revolution or Evolution: the challenges of conceptualizing patient and public involvement in a consumerist world. Health Expectations. 12(3) pp. 275-287.

[62] Von Bertalanffy, L. (1968) General Systems Theory: Foundations, Development, Applications. New York: George Braziller.

[63] Waring, A. (1996) Practical Systems Thinking.UK: Thomson Learning. 
[64] Warner, W. (1991) Improving interpretive validity of camera-based qualitative research, paper presented at the Qualitative Health Research Conference, Edmonton, Alberta.

[65] Warner, L., Rose, D. Mackintosh, G. and Ford, R. (2000a) Could this be you? Evaluating quality and standards of care in the impatient psychiatric setting. Mental Health and Learning Disabilities Care Vol. 4(3) pp. 89-92.

[66] Watson, A. (2001) Detained: Inspection of Compulsory
Mental Health Admissions. London, Department of Health.

[67] Weick, K.E. (1995) Sense making in organisations Thousand Oaks. CA: Sage.

[68] Wilson, I. 1994. "Strategic planning isn't dead - it changed". Long Range Planning, 27(4).

[69] Zadek, S Evans, R. Pruzak, P. (1997) Building corporate Accountability. London: Earthscan Publications Ltd. 